\title{
Sleep Pattern During Lockdown and COVID-19 Pandemic: An Unprecedented Stressful Situation
}

\author{
Surya Prakash Bhatt ${ }^{1 *}$, Randeep Guleria ${ }^{1}$ and Swati Allen ${ }^{2}$ \\ ${ }^{1}$ Department of Pulmonary Critical Care \& Sleep Medicine, New Delhi, India \\ ${ }^{2}$ Medicine, All India Institute of Medical Sciences, New Delhi, India
}

*Corresponding author: Surya Prakash Bhatt, Senior Research Scientist, Department of Pulmonary, Critical Care and Sleep

Medicine, All India Institute of Medical Sciences, New Delhi, India 110029

\section{ARTICLE INFO}

Received: 慧 June 18, 2021

Published: 蔧 June 30, 2021
ABSTRACT

Citation: Surya Prakash Bhatt, Randeep Guleria, Swati Allen. Sleep Pattern During Lockdown and COVID-19 Pandemic: An Unprecedented Stressful Situation. Biomed J Sci \& Tech Res 36(5)-2021. BJSTR. MS.ID.005919.

\section{Introduction}

Coronavirus disease 2019 (COVID-19) pandemic, caused by severe acute respiratory syndrome coronavirus (SARS)-COV2, is an unprecedented global public health problem [1]. In December 2019, SARS-COV2 emerged in Wuhan, China and on $11^{\text {th }}$ March 2020, the World Health Organization (WHO) declared COVID-19 a pandemic [2]. Although it is believed that this disease originated from bats, the exact cause of SARS-COV2 transmission is still unclear. The viral outbreak of disease in Asia has resulted in mass home confinement leading to a stressful situation among the mass population. Several activities including traveling (airways, railways, and metro services), schools, universities, and shops selling nonessential goods have been temporarily closed. Adapting to changes in lifestyle such as working from home, homeschooling children, reduced social interactions had interfered with our bodily rhythms. Sedentary lifestyle, less physical activity and changes of dietary patterns had a major impact on physical and mental health such as daily functioning and nighttime sleep [3]. Sleep is a critical biological process which is crucial to physical and mental health and is also an efficient functioning of the immune system. It is additionally a serious stimulator of emotional well-being, psychological state, and mental health, serving to beat stress, depression, and anxiety. It has been suggested that good sleep is a key indicator of good health. Also, psychological successfulness and sleep are affected by several socio-cultural factors [4].
Adequate social support has antecedently been reported to possess a positive result on psychological health and sleep [5]. The COVID-19 epidemic has become a stressor because this is a new viral infection and does not have any vaccine. In this brief review, we aim to discuss the dispairment of sleep patterns during COVID-19 pandemic and how to improve sleep quality by balancing circadian rhythm. We will also address the negative consequences of lockdown with respect to frequent fracturing of sleep affecting sleep quality and daytime functioning.

\section{COVID-19 and Pandemic: Dealing with New "Normal"} Life

Since its arrival in India, novel coronavirus talk has become a part of our day-to-day life. It has affected our routine greatly, this sudden change in our routine has affected our thinking ability to a greater extent. With lockdown imposed, we witnessed mental and emotional agony with respect to our family's well-being. All of these challenges came so quickly that we did not get the chance to acclimatize but rather had to adjust forcefully and absorbed what was called the "New Normal". Adjusting with the situation halfheartedly affected our Sleeping patterns to a greater extent. Although, before COVID 19, insomnia was a health problem but since lockdown, it has caused challenges even for those who had no prior sleeping problems, according to the Sleep Foundation. 
"Coronasomnia" is a new term that refers to sleep problems related to the pandemic and has deeply affected our sleep and mental health. It is important to understand that while we adjust to stayat-home or work-from- home orders, it is important to eat healthy food and to focus on "Stick to a consistent sleep-wake schedule". As per Sleep Foundation, sleep is critical to both physical health and for effective functioning of the immune system. It is a key promoter of emotional wellbeing and mental health. It also helps to beat back stress, depression, and anxiety [6]. Check your Anxiety levels: One of the biggest worries in the COVID-19 pandemic is the fear of catching the coronavirus or infecting close friends or family members especially who are older or who are in high-risk groups due to preexisting conditions such as obesity and its associated comorbidities.

Also, the uncertainty about economic recession affecting jobs, increasing unemployment can affect home expenditure and savings which can take a toll on mental health. Our mind keeps pondering over questions such as how the disease will spread, how many people are dead, how hospitals are managing the crisis, how long the lockdowns last, when the economy can recover, and all this data brings uncertainty and anxiety which disturbs our sleep routine as our mind constantly keeps thinking in the background. Struggle for Sleep: Unprecedented changes due to COVID-19 lockdown, many people are struggling to get their much-needed good night quality sleep. Forget people suffering from insomnia, this pandemic has played havoc with sleeping patterns of many healthy individuals. As we know that sleep and mental health are intimately connected in different ways as the neurochemicals which are responsible for a good night's sleep help manage our mood. A quality sleep also helps to boost our immunity. According to Apollo hospital, the following are a few reasons for consistent, good quality sleep which is an essential part of our lives for maintaining mental health. It plays a key role in effective immune system, enhancing brain function, improving our mood, and improving mental health.

In order to rest your mind for quality sleep amongst pandemic, we can follow certain tips which can help for good night REM sleep:

- Set Your Body's Circadian Rhythm: The body clock controls sleep, mood, and immunity. In order to keep it running on time, we have to set it every day which can be challenging when we are staying indoors during to COVID pandemic as well as lockdown. As we know that light plays a key role in sending signals to our body clock. In order to bring regularity in the body clock, we have to wake around the same time every morning. Our aim should be to get at least 30 minutes of sunlight after waking up. Before bedtime, maintain dim light to adjust your body clock accordingly. Take a warm bath or shower or read a book before bedtime.

- $\quad$ Eat Meals at a Fixed Time: One important way to keep your body clock running on time is to have your meals at a fixed time. Every meal including breakfast, lunch and dinner should be at a set time so that the body gets used to it. Planning your meal and exercising at same time have an added benefit to set your body clock. Also avoid spicy or heavy food before bedtime as heartburn and an upset stomach can interfere with your sleep.

- $\quad$ No Office in Bed: Although it may be a bit difficult due to space constraints, try not to do your office work from the bedroom. Reserve your bedroom for sleep purposes only. Also avoid watching TV in your bedroom as it can interfere with your sleeping pattern due to artificial light exposure. Turn off all electronic gadgets including mobile phones, laptops etc or minimize their use before sleep as they emit blue light which interferes with production of sleep hormone melatonin. Make your bedroom cool, calm, dark and quiet. Also avoid watching news/reading the newspaper before bed as it can initiate the thinking process in the brain in the background which can interfere with your sleep.

- Avoid Napping: Daytime napping can interfere with your quality REM sleep. However, whenever the body demands, short naps (less than 20 minutes) can help restore cognitive function and make you feel energized.

- Move your Body: As it is difficult to go for a morning/ evening walk, try some resistance/aerobic/dance etc at home. This will keep your muscles working. However, timing is crucial as vigorous workout before bed can interfere with your quality sleep. If possible, using the terrace for exercise is beneficial as the natural light helps to balance your natural internal clock.

- $\quad$ Meditate Daily: To keep your kind calm and relax, it is important to practice relaxation techniques such as deep breathing, mindful meditation, calming music, quiet reading, yoga etc which can help our internal clock by releasing hormones which promote sleep and reduce anxiety.

- $\quad$ Stay Socially Connected: Last but not the least is to stay socially connected. Stay in touch with your friends, family ones through social media, email, and phone calls.

\section{References}

1. Li R, Pei S, Chen B, Song Y, Zhang T, et al. (2020) Substantial undocumented infection facilitates the rapid dissemination of novel coronavirus (SARSCoV-2). Science 368(6490): 489-493.

2. Huang C, Wang Y, Li X, Ren L, Zhao J, et al. (2020) Clinical features of patients infected with 2019 novel coronavirus in Wuhan, China. Lancet 395(10223): 497-506.

3. Altena E, Baglioni C, Espie CA, Jason Ellis, Dimitri Gavriloff, et al. (2020) Dealing with sleep problems during home confinement due to the COVID-19 outbreak: Practical recommendations from a task force of the European CBT-I Academy. J Sleep Res 29(4): e13052.

4. Yao KW, Yu S, Cheng SP, Chen IJ (2008) Relationships between personal, depression andsocial network factors and sleep quality in communitydwelling older adults. J Nurs Res 16: 131-139.

5. Kent de Grey RG, Uchino BN, Trettevik R, Cronan S, Hogan JN (2018) Social support and sleep: A meta-analysis. Health Psychol 37(8): 787798.

6. Sleep foundation: A Onecare Media Company. 
ISSN: 2574-1241

DOI: $10.26717 /$ BJSTR.2021.36.005919

Surya Prakash Bhatt. Biomed J Sci \& Tech Res

(c) (P) This work is licensed under Creative BY Commons Attribution 4.0 License

Submission Link: https://biomedres.us/submit-manuscript.php

$\begin{array}{ll}\text { BIOMEDICAL } & \begin{array}{l}\text { Assets of Publishing with us } \\ \text { RESEARCHES }\end{array} \\ \text { - Global archiving of articles }\end{array}$

